\title{
OS PRINCÍPIOS NO DIREITO CONSTITUCIONAL BRASILEIRO: DIRETRIZES DE REGULAÇÃO A PARTIR DOS TRABALHOS DE RONALD DWORKIN E HANS-GEORG GADAMER \\ THE PRINCIPLES IN CONSTITUTIONAL LAW BRAZILIAN: REGULATORY GUIDELINES FROM THE WORK OF RONALD DWORKIN AND HANS-GEORG GADAMER
}

\author{
${ }^{1}$ Sheyla Yvette Cavalcanti Ribeiro Coutinho
}

\section{RESUMO}

A interpretação do Direito não pode estar condenada ao "decisionismo irracionalista", exigindo a demarcação de seu "campo correto" de extensão. Essa questão afirma a necessidade de uma "razão crítica", que seja responsável por delimitar os alcances interpretativos das Normas-Princípios no Sistema Jurídico Constitucional Nacional. A questão de fundo é a busca por uma hermenêutica constitucional, na qual se possa ancorar a legitimidade jurídico-normativa dos Princípios. Nesse caminho teórico, apresentam-se diretrizes para a delimitação de um núcleo objetivo de legitimação do Poder Jurisdicional, com base na "resposta correta" em Dworkin e na "correção da interpretação", proposta por HansGeorg Gadamer.

Palavras-chave: Dworkin, Gadamer, Crítica hermenêutica do direito

\begin{abstract}
The interpretation of the law can not is condemned to "decisionism irrationalist", demanding the demarcation of their "right field" extension. This question states the need for "critical reason", which is responsible for defining the interpretative scope of the Standards-Principles the National constitutional legal System. The bottom line is the search for a constitutional hermeneutics, in which to anchor the legal and normative legitimacy of Principles. In this theoretical path, we present guidelines for the definition of a core objective of legitimation of power jurisdictional, based on the "correct answer" in Dworkin and "correction of interpretation" proposed by Hans-Georg Gadamer.
\end{abstract}

Keywords: Dworkin, Gadamer, Hermeneutics of law critical

1Mestre pela Universidade Federal de Pernambuco. Universidade Federal de Pernambuco - UFPE, Pernambuco. Brasil - E-mail: shevlacoutinho@yahoo.com.br 


\section{CONSIDERAÇÕES INTRODUTÓRIAS}

O pensar inquieta: não há silêncio onde a vida está em ebulição. Está-se em ebulição. E, nesse estado, vê-se o vir-a-ser do texto. Confirma-se a pertença ao lugar da interrogação. Para seguir, precisa-se encontrar as linhas de um método. Não há como "descartar" um certo cartesianismo, para sobreviver às flutuações do pensamento e da criação. Organiza-se, doravante, as linhas centrais, que se percorrerá nessa aventura, que é dialogar com os textos, vivos, obtusos, "contemporâneos". Diga-se contemporâneos, posto que, presentes individualmente, fulguram coletivos, constituídos por tantos atores que, coletivamente, representam a mesma "Tlíada", motivados por suas "Helenas".

Inicialmente, como eclodiu o desejo de perseguir o texto - A Teoria dos Princípios no Processo Constitucional Brasileiro: diretrizes gadameriana-dworkinianas de regulação. Digase perseguir, haja vista que a revolução paradigmática ${ }^{1}$ da Teoria dos Princípios, no Direito nacional, muitas vezes, ao contrário de possibilitar maior extensão normativa de concreção, para a efetividade dos direitos fundamentais, vem, por "estelionato jurídico" de seus alcances, servindo para justificação de decisões amplamente discricionárias e até, como se verá adiante, "maquiavélicas" - com base em um processo de discricionariedade desregrada do intérpreteJuiz na aplicação da norma. A preocupação em torno dessa questão é um alerta de que não se pode, simplesmente, adotar uma postura de passividade em relação ao problema do relativis mo, mas que é necessária a afirmação da necessidade de uma "razão críica", que seja responsável por delimitar a viabilidade [validade ética], ou não, de determinados alcances da normaprincípio no Sistema Jurídico Constitucional. 
A questão de fundo formulada é a busca por uma hermenêutica constitucional, históricooperante $^{2}$, na qual se possa basear a legitimidade jurídico-normativa dos princípios utilizados para fundamentar a decisão judicial. Pergunta-se: Em que se diferenciam os "pré- conceitos" legítimos - hábeis a fundamentar a Decisão Jurídica - de todos os inumeráveis "pré- conceitos", cuja superação representa a inquestionável tarefa de uma razão crítica? Como "superar" a tentação do decisionismo voluntarista? Como preservar o alcance material da Constituição, diante do conteúdo polissêmico e aberto dos princípios, apresentados em forma de mandados de otimização ${ }^{3} ?$ ?

\footnotetext{
${ }^{1}$ Sobre a questão dos paradigmas adverte Gadamer (19998b, p.14): “Sabemos que, mesmo nas ciências empíricas, como Kuhn em particular o demonstrou, os conhecimentos novamente estabelecidos encontram resistências e na verdade permanecem por muito tempo 'ocultos' pelo paradigma dominante".

2 O princípio da Wirkungsgeschichtliche Bewusstsein (consciência dos efeitos da historicidade humana, ou consciência em que a história at ua constantemente, ou consciência historicamente operativa) reside, grosseiramente, em dois aspectos: primeiro, a percepção dos efeitos da história nos contextos onde o entendimento humano tem lugar, e em segundo momento, na percepcão de nosso próprio entendimento sendo afetado por esses efeitos. Essa acepção tem algumas consequências efetivas para a filosofia crítica. Não a priva de suas percepções ou finalidades mas est abelece limites para sua própria tarefa crítica. A filosofia crítica, em especial, a epistemologia, acredit ou proficuamente poder catalogar os esforços humanos para o entendimento racional, detectaros defeitos (erros) que impediam tal tarefa e, finalmente, superá-los, apresentando os caminhos para um conhecimento seguro e claro. Gadamer (1999) apresenta, em contrapartida ao historicismo, o termo wirkungsgeschichtlich no qual entende a consciência verdadeiramente histórica fora dos matizes da aut orreflexão total do espírito hegeliana. Gadamer (1999), valendose da estrut ura geral da compreensão em Heidegger, deu uma nova orientação para o conteúdo metodológico da hermenêutica, caminho esse totalmente diverso daquela hermenêutica geral das ciências do espírito. Com Heidegger, desenvolveu-se, em contrapartida ao paradigma da linguagem como informação, outro paradigma de pensamento, a partir do qual a linguagem representa o constitutivo fundamenta de toda experiência real. O que Heidegger propôs, sem negar o valor do caráter instrumental da linguagem, foi voltar a pensar a relação originária do homem com a linguagem. A descida aos fundamentos implica perguntar de que modo, por meio da linguagem, o ser se desvela a nós e se nos dá. Para Heidegger, trata-se, muito mais, de fazer uma experiência com a linguagem que é fundamentalmente diferente de "conhecer" a linguagem no sentido científico ou filosófico. Sobre isso, Gadamer (2002, p. 176) completa: "só podemos pensar dentro de uma linguagem e é justamente o fato de que nosso pensamento habita a linguagem que constitui o enigma profundo que a linguagem propõem ao pensar". 3 Para Robert Alexy (2008, p. 90), o ponto decisivo na distinção de regras e princípios é que princípios são normas que ordenam que algo seja realizado na maior medida possível dentro das possibilidades jurídicas e fáticas existentes. Princípios, os são, por conseguinte, mandamentos de otimização, que são caracterizados por poderem ser satisfeitos em graus variados (...)" [grifo do autor].
} 
A reivindicação da antidiscricionariedade decisória deve se articular à reivindicação de uma hermenêutica antirrelativista. Com base nela, pluralidade e universalidade ${ }^{4}$ não são excludentes. Por dentro dessa concepção, não se pode admitir sentidos exclusivamente arbitrários à interpretação. A interpretação do Direito não estaria condenada a um "decisio nis mo irracionalista", exigindo uma demarcação de um "campo correto" ${ }^{5}$ de extensão. Nessa direção de hermenêutica antirrelativista, há de se perquirir a legitimidade valorativa do Direito, que nasce em um contexto intersubjetivo de fundamentação. Ilustra-se a transição paradigmática do liberalismo clássico para o paradigma transindividual do Estado Democrático de Direito, que exige a socialidade e a eticidade das relações sociojurídicas. Nesse escopo, a dimensão da pré-compreensão $^{6}$ do intérprete não pode ser tratada como um campo de especulação "perdida", afetando a segurança jurídica e a unidade do texto constitucional. Essa "Nova Hermenêutica" tem seus substratos e limites em uma teoria material de valores, onde se busca concretização do preceito constitucional sem reduzi-lo ao "charme" do decisionismo arbitrário $^{7}$.

\footnotetext{
4 A pergunta que se faz é como a reivindicação da pluralidade e a consequente valorização do outro, articula -se com a reivindicação de universalidade. São ambas - pluralidade e universalidade-excludentes? A essa indagação talveza filosofia de Gadamer tenha uma resposta a nos oferecer, quando esclarece que:“(...) como se fossemduas pontas de ummesmo fio a coisa [o Universal] e o intérprete que a projeta estão ao mesmo tempo vinculados e distanciados, istoé, manifestam a tensão entre estranheza e familiaridade que os marca mutuamente. (...) A tensão permanente entre a objetividade da coisa, constatada por sua distância histónica, e o seu pertencimento a uma tradição marcam, tanto a inesgotabilidade de possibilidades de manifestações de sentido, quanto a finitude ontológica do intérprete" (ALMEIDA, 2000, p.66).

5 Vide Streck (2007, p. 141 et. seq.).

6 A pré-compreensão está em constante reorientação, permanece no jogo histórico e não cede às pressões da completa reflexão, em nome da soberania de uma certeza racional e normativa. A compreensão pressupõe uma pré-compreensão, e ela não ocome semuma dimensão projetiva que antecipa o sentido:“(...) O círculo hermenêutico éum círculo rico em conteúdo (inhaltlich erfullttt) que reúne o intérprete e seu texto numa unidade interior a uma totalidade em movimento (processual whole). A compreensão implica sempre uma pré- compreensão que, por sua vez, é prefigurada por uma tradição deteminada em que vive o intérprete e que modela os seus preconceitos (GADAMER, 1998b, p.13).

7É o cenário do que Paulo Bonavides (2008, p.595): expõe como uma "Nova Hermenêutica de Concretização",

oniunda doPrincípio da Unidade daConstituição: "A Corte de Karlsnuhe sentenciou"Não sepodeconsiderarinsuladamente uma estipulação singular da Constituição, nem pode ser ela interpretada 'em si mesma', senão que deve manter 'conexão' de sentido com as demais prescrições da Constituição, formando uma unidade interna".
} 


\section{A fundamentalidade material da Constituição.}

A conceituação clássica de Jurisdição ${ }^{8}$ - ius dicere - afirma que o Już é a "boca da lei” e deve funcionar como aquele elemento imparcial, objetificado pela norma geral e abstrata criada pelo Legislador. Assim, a norma "toma" o Juiz, para que possa ser aplicada ao caso concreto. A atividade judicante submete-se ao dever-ser da norma, de forma prolongada e passiva. Araújo Cintra, Grinover e Dinamarco (2008, p. 148) esclarecem: “(...) como essas pessoas [os Júzes] não agem em nome próprio [atividade é substitutiva das partes em litíg io], mas como Órgão do Estado, a sua imparcialidade é uma exigência da lei (...)". Essa abordagem clássica da Jurisdição vê a sentença como a "norma individual que particulariza a norma geral" (MARINONI, 2008, p. 105). Trata-se de considerar a norma como somente o texto da lei, desconectada de seu programa normativo.

Desde as primeiras Constituições escritas do final do século XVIII ${ }^{9}$, até meados do Século XX (Fim da $02^{a}$ Guerra Mundial), permanecem os métodos tradicio nais de interpretação do Direito, nos quais a tarefa de percepção do sentido da norma se movia no interior da própria norma. O intérprete não observava os "limites" e o "teto" hermenêutico da norma constitucional. Tratava-se de um paradigma que professava o culto da legalidade, sistemático, lógico, e, por isso, não se expunha às crises e às tensões existenciais, propugnando uma interpretação do Direito, ancorada nos métodos clássicos, enunciados por Savigny (BONAVIDES, 2008, p. 46465). Com o pós-guerra, começa-se a questionar a utilização de "novos" métodos de interpretação

\footnotetext{
${ }^{8}$ Jurisdição é uma das funções do Estado, mediante a qual este se substituiaos titulares dos interesses em conflito para, imparcialmente, buscar a pacificação do conflito que os envolve, comjustiça. Ess a pacificação é feita mediante a atuação da vontade do direito objetivo que rege o caso concreto para ser solucionado; (...) (ARAÚJO CINTRA; GRINOVER; DINAMARCO, 2008, p. 148).

9 Paulo Bonavides (2008, p. 225 et. seq.) leciona DIFERENTES PARADIGMAS DO "ESTADO DE DIREITO", com as características que podem ser assimminimamente resumidas: a) Estado de Direito Liberal: Século XVIII - 1776 (Revolução. Americana) / 1791 (Revolução Francesa)/Escola da Exegese - Juiz como "boca da lei” - O Juiz e a interpretação literal da lei - Juiz longa manus da lei; b) Estado Social - após a 01 a Guerra Mundial Intervenção do Estado nas relações sociais/econômicas e laborais/superação da ideia de submissão do fato (premissa menor) à norma (premissa maior) / (re)materialização do Direito Constitucional/ Métodos de interpretação em Savigny (metade do século XIX - gramatical/histórico/lógico/sistemático), que levou ao "esforço" de Kelsen para manter os limites da discricionariedade do Juiz (Teoria Pura do Direito)/Moldura ou quadro do dever-ser da norma, como limite interpretativo. Também, a Teoria do Positivis mo Jurídico de Herbert Hart; c) Estado Democrático de Direito - Fim da 02 a Guerra Mundial, até os dias de hoje - Pós-Positivismo Jurídico/ "operatividade" hermenêutica, como alargamento da margem de criatividade no Direito, através da utilização das técnicas de ponderação e de argumentação. A base dessa "virada epistemológica" se dá pela crescente complexidade das demandas da sociedade desse pós-guerra.
} 
do Direito Constitucional: a partir do estudo da principiologia constitucional e do caráter aberto/polissêmico e indeterminado dos princípios, incapazes de atender aos "casos simples" das normas-regras, que se orientavam pelo esquema lógico (horizontal) do tipo - "se A, então B". A guerra mostrara que os fatos "da vida" e a sua rebeldia imperavam diante dos esquemas-base da racionalidade positiva, quais sejam, abstração e dedução lógica. Ocorre o que Lyotard (1993, p. 03) definiu como a deslegitimação dos grandes relatos da modernidade (metadiscursos) e se inicia uma "virada epistemológica" também no campo sociojurídico. Prementemente, essa "nova" abordagem teórica, cunhada de Neoconstitucionalismo [ou, PósPositivismo Jurídico - com uma principio logia ancorada na dignidade humana, na solidariedade social e nos direitos fundamentais] incorpora o cabimento dos campos de "valoração" e de "justiça”, com sua centralidade marcada pela Força Normativa da Constituição ${ }^{10}$, amparada, em especial, pela axiologia da existência humana digna e nos princípios dela derivados. Com essa abordagem, a ética e os valores começam a voltar ao Direito. Ilustra Marinoni (2008, p. 48-49):

A obrigação do jurista não é mais apenas a de revelar as palavras da lei, mas a de projetar uma imagem, corrigindo-a e adequando-a aos princípios de justiça e aos direitos fundamentais. (...). O neoconstitucionalismo exige a compreensão crítica da lei em face da Constituição (...). Essa transformação crítica da lei, ao dar o jurista uma tarefa de construção - e não de simples revelação - confere-lhe maior dignidade e responsabilidade, já que dele se espera uma atividade essencial para dar efetividade aos planos da Constituição, ou seja, aos projetos do Estado e às aspirações da sociedade.

\footnotetext{
${ }^{10}$ A tópica no Direito Constitucional Contemporâneo tem na Alemanha os seus grandes Mestres, entre os quais figuram: Konrad Hesse (Força Normativa da Constituição); Friedrick Müller (com um novo método de interpretação constitucional, que ele mesmo denominou de estrutural-funcionalista [Normativo-estruturante] e Häberle [a Constituição aberta - sistema de interpretação constitucional mais antiformalista que se conhece]. Segundo Konrad Hesse as normas constitucionais possuem uma força própria (densidade material): "Quanto mais a ordem constitucional corres ponde às realidades da situação his tórica, quanto maior é a dis posição de reconheceros conteúdos da Constituição como obrigatórios e quanto mais firme é a disposição de atualizar esses conteúdos, também contra as resistências, tanto mais e mais seguro aquelas ameaças poderão ser evitadas ou rechaçadas" (HESSE apud STRECK, 2005, p.252). A interpretação constitucional é concretização, na qual o concreto é individualizado: concretizar o sentido da norma dentro das condições de uma situação de fato determinada. Em detrimento do método tópico-problemático, que "valoriza" o problema, o método hermenêutico-concretizador valoriza o comando normativo e sua individualização no mundo. Interpretar e aplicar são um único processo. Para Hesse, "uma lei não deve ser declarada nula quando ela pode ser interpretada em consonância com a Constituição. Essa consonância existe não só, então, quando a lei, sem uma consideração dos pontos de vista jurídicoconstitucionais, admite uma interpretação que é compatível com a Constituição" (HESSE apud STRECK, 2005, p.252).
} 
Dessa forma, o intérprete constitucional não pode separar o programa normativo, inserido nas constituições, da realidade social. Essa constitucionalização do Direito material [e processual] busca superar a antinomia clássica Direito NaturaVDireito Positivo (BONAVIDES, 2008, p. 276). Representa um salto para uma Teoria Material da Constituição, constituída por uma hegemonia normativa dos princípios, onde esses aparecem definitivamente como normas valores de maior positividade nas Constituições que nos Código e, por isso, providos do mais lato peso, por apresentarem "eficácia suprema" (BONAVIDES, 2008, p. 276). Neh, os fatos "da vida" e "a sua rebeldia" insurgem, perante aqueles esquemas positivistas.

Em Hans-Kelsen, a norma é um ato de vontade, propugnando a defesa de uma opção voluntarista (um ato volitivo, de decisão, um Sinngebung) e não cognitiva (um ato intelectivo, um Sinnverständnis), do ato de realização do Direito. Ele rechaça a tese da antinomia tradiciona 1 entre criação e aplicação do direito. A Teoria Pura do Direito, ao ver a função judicial como criadora do direito, põe em xeque a falácia, resultado de um "entendimento equivocado", de que Kelsen haveria encarado o Już como a "boca que pronuncia as palavras da ki” - e, "nisso reside a maldição de sua tese", para Streck (2013, posição 1807). Assim, em Hans- Kelsen, o intérprete, desde logo, guia-se mais por sua vontade do que por sua intelecção. Para ele, quando o Jü̇ "decide", por uma das várias possibilidades interpretativas, ele sempre age de forma discricionária, realiza uma escolha (ou preferência), que está fora da esfera técnico-teórica, mas sim, pertence à Políica do Direito (BONAVIDES, 2008, p. 452). A interpretação do Direito é uma questão de "moldura semântica", repleta de subjetivismos, com base em uma razão solipsista $^{11}$. Esse é o "desvio" interpretativo, que é, na esfera pragmática, impossível de correção. Dessa maneira, o único modo de corrigi-lo era a realização de uma "terapia lógica" do Direito. Por isso, Kelsen "prefere" afastar-se da realização fática do Direito, fazendo de sua Teoria Pura uma "Ciência do Direito", "purificada", através de um rigoroso tratado de lógica, onde as questões pragmáticas eram reservadas à discricionariedade jurídica (STRECK, 2013, posição 1798-1807). Pertinente no momento, a justa elucidação de Streck (2013, posição 1807), para quem Kelsen "abandonou o principal problema do Direito: a interpretação concreta ao nível da aplicação" [grifo nosso]. Assim, à luz kelnesiana, a interpretação jurídica seria aquele

\footnotetext{
${ }^{11} \mathrm{O}$ processo é retrato da consciência do Juiz, a partir de seus critérios próprios de racionalidade. Frise-se a própria polissemia da palavra "racionalidade", principalmente, após o materialismo-dialético e as filosofias da linguagem. Defende-se a tese de que "só existe" o que está na consciência do julgador.
} 

ato de vontade poder (Der Wille zur Macht), movimento intencional da vontade enquanto projeto para atingir um fim: vontade é intencionalidade finalística. Também, Max Weber (1964) reconhece a intencionalidade na relação entre indivíduo e sociedade, procurando tratar dos significados subjetivos do ato social Para Weber, a sociedade é fruto de uma interrelação de atores sociais, onde as ações de uns são reciprocamente orientadas em direção às ações dos outros. Nesse sentido, Weber (1964, p. 33) conceitua ação social, enquanto

todo o comportamento humano quando e até onde a ação individual lhe atribui um significado subjetivo. A 'ação' neste sentido pode ser tanto aberta quanto subjetiva. (...) A 'ação' é social quando, em virtude do significado subjetivo atribuído a ela pelos indivíduos, leva em conta o comportamento dos outros e é orientada por ele na sua realização.

Importante frisar como Weber influencia os trabalhos de Hans-Kelsen, em especial, na teoria da voluntariedade, subjacente à interpretação jurídica. A Sociologia Compreensiva weberiana alerta que não existe uma análise cultural apartada dos fenômenos sociais, “independente dos pontos de vista especiais e parciais, segundo os quais, de forma explícita ou tática, consciente ou subconsciente, aqueles são selecionados e organizados para propósitos expositivos. Todo conhecimento da realidade cultural, como pode ser visto, é sempre conhecimento a partir de pontos de vista específicos" (WEBER, 1949, p. 72).

A "ratio subjetiva" da interpretação judicial foi notícia"12, no site do Conjur, em 2012, descrevendo-se como a ideologia pessoal define, muitas vezes, as decisões de Juízes. Segundo a pesquisa realizada pela Universidade Federal do Paraná, os Júzes paranaenses entrevistados julgam os casos concretos, muito mais, baseados em critérios pessoais do que na Teoria que os sustenta. Sobre os resultados da pesquisa, Lenio Streck comenta:

Os dados não surpreendem. Apenas confirmam a crise de paradigma que venho denunciando há anos. Nossa formação jurídica, nosso ensino, nossas práticas, encontram-se arraigadas a um paradigma filosófico ultrapassado. Sei que é difícil dizer isso, mas falta filosofia. Falta compreensão. Nosso imaginário jurídico está mergulhado na filosofia da consciência. Nele, cada juiz é o "proprietário dos sentidos". É um equívoco dizer que sentença vem de sentire. Essa é uma das grandes falácias construídas no Direito. É o que eu chamo de "solipsismo", que é a tradução de selbstsüchtiger, o sujeito egoísta da modernidade.

12 Critérios subjetivos: ideologia pessoal define decisões de juízes, diz estudo. disponível em: < http://www.conjur.com.br/2012-ju 1-06/ideologia-pessoal-define-decisoes-juizes-estudo-ufpr $>$ acesso em: 
Do ponto de vista processual constitucional contemporâneo ${ }^{13}$, ancorado no que se concebe, de uma forma geral, como "principiologia dos valores", a norma jurídica contida na sentença "não pretende ser pensada como uma norma que regula o caso concreto, nem mesmo quando é fruto do controle constitucional; (...)" (MARINONI, 2008, p. 101). Essa norma está longe de ser a particularização da lei. Continua a esclarecer Marinoni $(2008,101)$ :

[Essa norma] pode ser dita uma norma jurídica criada diante do caso concreto, mas não uma norma individual que regula o caso concreto. (...) [A norma jurídica] serve para explicar a conformação da lei e da legislação aos princípios constitucionais de justiça e aos direitos fundamentais [grifo do autor].

Por isso, considerar a principiologia constitucional, a partir da fundamentalidade material da Constituição, ancorada na força normativa dos princípios, não pode significar, de nenhuma maneira, a aceitação irresponsável de uma "panprincipiologia oportunista" (STRECK, 2012), cuja discricionariedade ilimitada se afasta dos próprios feixes de valores constitucionais. Propiciar tal poder ao Estado-Juiz é rasgar todos os valores albergados pela Magna Carta. A onisciência e a onipotência de uma forma de poder é indício de transfiguração democrática e da criação de um superpoder do Estado, segundo caracteres especialmente maquiavélicos ${ }^{14}$.

\footnotetext{
13 Os princípios foram trazidos para o centro do sistema constitucional e "ganharam” o status jurídico de norma, deixando o arcabouço meramente valorativo, sem aplicabilidade e eficácia. Essa perspectiva "pós-positivista" e principiológica do Direito deu ensejo à formaçã̃o de uma moderna hermenêutica constitucional. (BARROSO, 2006, p. 34).

14 “(...) Na prática do foro se constat a tal realidade cotidianamente, pois é ali, situadas dentro de um contexto fático, que as palavras ganham vida e recebem sentido não rar o desvirtuados daquilo que se ambicionou quando da sua utilização nos textos legais. Pior équando a coisa degringola e o intérprete crê estar aut orizado a avançar aventureiro para além das possíveis respostas autênticas que o texto oferece, assujeitando-o segundo seus anseios, torcendo sua estrutura para atingir sentidos cujas fundações só se encontram em sua própria mente, algo que, infelizmente, é corriqueiro em uma justiça como a brasileira, na qual se mantém habitual o jargão "direito é aquilo que os tribunais dizem que é”. (DELFINO; FERREIRA LOPES, 2015).
} 


\section{Uma Revolução Copernicana: A Hermenêutica Clássica versus a normatividade dos Princípios.}

A tarefa de conceituar princípios torna-se árdua ${ }^{15}$, face à carga ideológica que envolve o tema: é praticamente impossível chegar a um denominador comum, para mais, quando se analisa a questão da força normativa dos princípios, como se verá adiante. Segundo Humberto

Ávila (2015 p.55) vários são os autores, que tangenciaram a definição das espécies normativas - regras e princípios - alguns, com grande repercussão doutrinária. Ávila (2015, p. 55) cita, dentre outros juristas, Josef Esser, para quem os princípios são aquelas normas que estabelece m fundamentos para que determinado mandamento seja aplicado. Para Esser ${ }^{16}$ (1990) apud Ávila (2015, p.55), o critério distintivo dos princípios em relação às regras seria a função de fundamento normativo para a tomada de decisão. Também, segundo Claus-Wilhelm Canaris ${ }^{17}$ (1983) apud Ávila (2015, p. 56), duas seriam as características capazes de afastar as normasprincípio das normas-regras: a) Em primeiro lugar: o conteúdo axiológico explícito, o que os tornaria carentes de regras para sua concretização; b) o seu modo de interação com as outras regras: a formação do seu sentido depende de um processo dialético de complementação e limitação. Até mesmo o fecundo jurista Noberto Bobbio ${ }^{18}$ (s/d) apud Bonavides (2008, p. 263264), grifo nosso), inicialmente, não traçara uma posição clara sobre a normatividade dos princípios. A posteriori, na sua Teoria do ordenamento Jurídico, supre essa "falta" e escreve:

\footnotetext{
15 Na contemporaneidade brasileira, há autores civilistas que abandonama antiga dogmática dos civilistas clássicos, centrada no individualismo e no patrimonialismo, realizando uma abordagem da Teoria Geral do Direito Civil, sob o norte dos novos princípios constitucionais, trazidos pela Constituição Federal de 1988, dentre outros: Cristiano Chaves (2011) e Flávio Tartuce. Esse último autor completa (2007, p.117): “(..) Há, assim, não uma invasão do Direito Constitucional sobre o Civil, mas sim uma interação simbiótica entre eles (...)”. Nessa toada, Paulo Lôbo (2005, p.2), comenta: (...) Antes, havia uma distinção; hoje, a unidade hermenêutica, tendo a constituição como ápice conformador da elaboração e da leg islação civil. A mudança de atitude é substancial: deve o jurista interpretar o Código Civil segundo a Constituição e não a Constituição segundo o Código Civil, como ocorria com frequência (e, ainda, ocorre). A mudança de atitude também envolve certa dose de humildade epistemológica. Com base nessa "força constitucionalizante" dos institutos de Direito Civil, há de considerar se EXISTE, ou não, diferença entre princípios gerais de direito e princípios fundamentais do sistemajurídico. Os que professam uma diferença expõem: a) Os princípios gerais de direito são " meros mecanismos de preenchimento de lacunas, sem qualquer conteúdo valorativo e com características u niversais. Assim, os princípios gerais são os mesmos em qualquer sistema jurídico, in spirando métodos para colmatar vazios normativos (CHAVES DE FARIAS, 2011, p. 127); b) Os princípios fundamentais do sistema jurídico "são as normas jurídicas com conteúdo valorativo (axiológico), aberto, a ser preenchido no caso concreto, possuindo nítida força vinculante, normativa. Ou seja, os princípios fundamentais são normas jurídicas e obrigam, vinculam” (CHAVES DE FARIAS, 2011 , p.
}

127); c) Assim, há uma diferença entre os princípios gerais de direito e os princípios fundamentais do sistema jurídico. Os princípios gerais somente serão utilizado quando houver um vazio normativo, ou seja, quando não existir, para umdeterminado caso concreto, uma norma jurídica, quer seja uma norma-regra ou uma normaprincípio. Quer dizer que: somente serão utilizados os princíp ios gerais, quando ausente umprincípio fundamental. No Direito brasileiro, há quemprofesse que, no constitucionalismo contemporâneo, os princípios gerais de direito são os próprios princípios gerais contidos na Carta Constit ucional. Como exemplo, Lucas Abreu Barroso apud Tartuce (2007, p. 55-56) chega a advogar a revogação do art. $4^{\circ}$ da Lei de Introdutória às Normas de Direito Brasileiro, ao argumento de que os princípios gerais de direito, na ótica do constitucionalismo contemporâneo, são os próprios princípios gerais contidos na Carta Constitucional, que, a toda evidência possuem força normativa: “(...) os princípios gerais de direito, na realidade pós-positivista, consubstanciam-se nos princípios gerais de direito e têm eficácia normativa (....)”. Assim, poder-se-ia dizer que, para quemadvoga a não revogação do art. $4^{\circ}$ da LINDB, deve entender a expressão “lei” como NORMA-JURÍDICA [norma-regra ou norma-princípio constitucional fundamental] e, em seguida, respeitar a ordem do art. $4^{\circ}$ da LINDB. Assim, na omissão da NORMA- JURÍDICA, o Juiz se valerá da analogia, dos costumes e dos princípios gerais do direito para preenchê-la. Flávio Tartuce (2007, p. 55-56) afirma que a ordem do art. $4^{\circ}$ da LINDB continua sendo a regra, o que deve, inclusive, manter-se para a primeira fase dos Concursos Públicos, ora o entendimento clássico e, ainda, majoritário. Completa Tartuce (2007): para os que seguem aEscolado “Direito CivilConstitucional”, os princípios constitucionais [que são os próprios princípiosgerais contidos na Carta Constitucional] NÃO seriam destinadas apenas excepcionalmente ao intérprete na ausência de norma ordinária específic a, como os princípios gerais do direito. Então, a ordem constante do art. $4^{\circ}$ da LIND é inaplicável. Ainda, Lenio Streck (2013, posição 2031) leciona que os princípios gerais do direito não possuem força deôntica, mas são instrumentos matematizantes de composição das falhas do sistema, sendo acionados apenas em casos de 1 acunas ou de obscuridade da previsão legislativa.

16 ESSER, Josef. Grundsatz und normin der richterlichen fortbildung des privat-rechts. Türbingen, Mohr, Siebeck, 1990

17 CANARIS, Claus-Wilhelm. Systemdenken und systembegriff in der jurisprudenz. Berlin: Duncker und Humblot,

1983

18 BOBBIO, N. Teoria dell’ ordinamento giuridico. Turim: Giappichelli Editore, s/d. 


\begin{abstract}
Os princípios gerais são, a meu ver, nor mas fundamentais ou generalíssimas do sistema, as normas mais gerais. O nome de princípio induz em engano, tanto que é velha questão entre jurista se os princípios são ou não nor mas. Para mim, não há dúvida: os princípios ge rais são normas como todas as demais. E esta é a tese sustentada também pelo estudioso que mais amplamente se ocupou da problemática, ou seja, Crisafulli. Para sustentar que os princípios gerais são nor mas, os argumentos vêm a ser dois e ambos válidos: antes de tudo, se são normas aquelas das quais os princípios gerais são extraídos, através de um procedimento de generalização sucessiva, não se vê que não devam ser normas também eles: se abstraio de espécies animais obtenho sempre animais, e não flores ou estrelas. Em segundo lugar, a função para a qual são abstraídos e adotados é aquela mesma que é cumprida por todas as normas, isto é, a função de regular um caso. Para regular um comportamento não regulado, é claro: mas agora servem ao mesmo fim para que servem as normas expressas. $\mathrm{E}$ por que então não deveriam ser normas? [grifo nosso].
\end{abstract}

Paulo Bonavides $(2008,259)$ organiza uma linha do tempo da juridicidade dos princípios, que, passa por três fases de evolução, na sua acepção: a Jusnaturalista; a Positivis ta e a Pós-Positivista: a) Jusnaturalista - Os princípios são os axiomas advindos da reta razão: conjunto de verdades objetivas derivadas das lei divina [Escolástica]e humana [Racionalis moIluminista] (2008, p. 261); b) a Positivista - Nessa fase, os princípios gerais de direito equivalem aos princípios, que informam o Direito Positivo, e the servem de fundamento. São sucessivas generalizações de regras particulares; não são ditados peh razão, nem se constitue m de um Direito Natural ou Ideal, mas são positivados no ordenamento. Nessa fase, são suas características: Carência de normatividade; irrelevância jurídica; são fonte normativa subsidiária da lei (2008, p. 262-263); c) Pós-Positivista - Princípio é Norma [Normas- Princípio]: impõe obrigações. Princípios são normas primárias e não fontes formais secundárias à lei [Doutrina Civilista Clássica/Doutrina Liberal]: são normativos - portanto, normas de aplicação imediata. Nessa tradição Pós-Positivista, capitaneada, no mundo anglo-americano, pelo eminente jurista de Harvard, Ronald Dworkin, “aparecem” as críticas do Positivismo ortodoxo (general attack on Positivism), e, paralelamente, da Doutrina do Direito Natural Em seguida, o jurista alemão, Robert Alexy, ao estudar uma Teoria Material dos Direitos Fundamentais, partindo das análises de Dworkin, e, com base na jurisprudência do Tribunal Constitucional Alemão, afirma que a solução de conflitos entre princípios não se resolve na imediata relação entre o princípio com peso relativo maior, mas é estabelecida em função da ponderação entre os princípios colidentes. $\mathrm{Na}$ "instituição" dos princípios como normas jurídicas, conclui-se que Robert Alexy e Ronald 
Dworkin expõem, cada qual à sua maneira, uma específica Teoria Crítica da Principiologia Jurílica. Para Dworkin, o Jüz não dispõe de uma margem de liberdade para aplicar o Direito, como the parece mais justo, ou, mais razoável. Em termos técnicos, Dworkin não reconhecia ao juiz o chamado poder discricionário no ato decisional. Nesse sentido, para Dworkin, a interpretação principiológica da norma não cria/aumenta a margem de discricionariedade, ao contrário, deve conter essa subjetividade do Juiz, em busca da norma "correta" aplicável ao caso concreto, com base naquela que melhor se ajuste à integridade do Direito. Para Alexy, os princípios são mandamentos de otimização, ou seja, ordenam que algo seja realizado na maior medida possível, dentro das possibilidades jurídicas e fáticas plausíveis. Segundo a Teoria Alexyana, o sopesamento retira a carga de arbitrariedade da decisão, pois que respeitaria a lei de colisão, aplicável ao caso concreto em análise e que, com o tempo, vai se tornando madura na Doutrina e Jurisprudência:

E a lei de colisão demonstra que o sopesamento conduz a uma dogmática diferenciada dos diferentes direitos fundamentais: no caso de colisão é necessário definir uma relação condicionada de preferência. A ela corresponde uma regra de grau de concretude relativamente alto. Por meio dos sopesamentos da jurisprudência e de propostas de sopesamento aceitas pela Ciência do Direito, surge, com o passar do tempo, uma rede de regras concretas atribuídas às diferentes disposições de direitos fundamentais, as quais representam uma importante base e um objeto central da dogmática. (ALEXY, 2008, p.175).

Respeitando-se as defesas do próprio Alexy à sua Teoria, concorda-se, nesse texto, que ela é "apenas" uma repristinação da "velha discricionariedade positivista", com ênfase no protagonismo judicial, onde "o sub-jectum" da interpretação continua "sendo o juiz e suas escolhas" (STRECK, 2013, posição 1904).

Seguindo a linha do tempo da juridicidade dos princípios, Paulo Bonavides (2008, p. 264) leciona sobre a constitucionalização dos princípios gerais de direito, chegando até o que define como sendo uma terceira fase para os princípios - que passam a ser tratados como Direito, a partir da nova ordem pós-positivista, instalada nas últimas décadas do século XX. À luz de Paulo Bonavides (2008, p. 256), a concepção Positivista de princípio conserva um "defeito capital", qual seja: "a omissão daquele traço que é qualitativamente o passo mais largo dado pela doutrina contemporânea para a caracterização dos princípios, a saber, o traço de sua normatividade". Complementa Streck (2013, p. 1816), após o segundo pós-guerra, inicia-se uma Constituição normativa, invasora da legalidade e fundadora do espaço público democrático 
(...)", onde reside "uma concepção da legalidade que só se constitui sob o manto da constitucionalidade" [grifo do autor].

Nesse momento, com lucidez, vislumbra-se que os princípios, quando da análise não estritamente positivista, seriam, vetores destinados à operatividade jurídica, com base em uma Teoria Críica específica, que os procura estudar. $\mathrm{Na}$ abordagem clássica, de outro lado, segundo, por exemplo, Orlando Gomes ${ }^{19}$ (1995) apud Chaves de Farias (2011, p.111) ${ }^{20}$ os princípios são fontes secundárias do Direito ${ }^{21}$. As normas [regras positivas] se diferenciam dos princípios, pois regem situações subjetivas de vínculos. Dessa forma, a Civilística Clássica, não entende os princípios como normas primárias. Para mais, sobre isso, veja-se a doutrina de Tercio Sampaio Ferraz Júnior (2003. p.240):

(...) os princípios gerais de direito constituem reminiscência do direito natural como fonte. Há autores que os identificam com este, outros que os fazem repousar na equidade, enquanto sentimento do justo no caso concreto. Sua formulação é indefinida. Há quem os reduza, em última análise, aos famosos preceitos romanos: honeste vivere, alterum non laedere, suum cuique tribuer $e^{22}$. De qualquer modo, ainda que se entenda que possam ser aplicados diretamente na solução de conflitos, trata-se não de normas, mas de princípios. Ou seja, não são elementos do repertório do sistema, mas fazem parte de suas regras estruturais, dizem respeito à relação entre as normas no sistema, ao qual conferem coesão. [grifo nosso].

Do que se viu, o ponto nevrálgico da transformação, por que passaram ao logo do tempo os princípios, reside na sua normatividade. Constituem-se "normas-valores" do mais alto peso, postos como normas supremas do ordenamento. Ensina Paulo Bonavides (2008, p. 288) que esse é o "passo final da incursão teórica" da Teoria dos Princípios:

(...) a demonstração do reconhecimento da superioridade e hegemonia dos princípios na pirâmide normativa; supremacia que não é unicamente formal, mas, sobretudo material, e, apenas possível na medida em que os princípios são compreendidos e equiparados e até mesmo confundidos com os valores, sendo, na ordem constitucional dos ordenamentos jurídicos, a expressão mais alta da normatividade que fundamenta a organização do poder.

\footnotetext{
19 GOMES, Orlando. Introdução ao direito civil. Rio de Janeiro: Forense, 1995.

20 Orlando Gomes (1995) apud Chaves de Farias Rosenvald (2011, p.111), após enfatizar a inexistência de consenso na classificação das fontes formais do Direito, destaca que "alguns doutrinadores reduzem-nas à lei e ao costume; outros acrescentam a jurisprudência e os princípios gerais do Direito; e os mesmos precisos inclue m ainda a doutrina e a equidade".

21 Também, Caio Mário da Silva Pereira apud Chaves de Farias e Rosenvald (2011, p.112), tomando por base o art. $4^{\circ}$ da Lei de Introdução às normas do direito brasileiro, compreende como fontes formais do direito a lei (emsentido amplo, significando a norma jurídica, englobando, não apenas a norma legal, mas também os decretos, regulamentos, portarias, atos administrativos, contratos sociais, convenções de condomínios etc.), a analogia, os

costumes e os princípios gerais de direito. Ademais, há de se atentar para o fato de que as fontes formais se subdividemem principal e acessória. Aquela (fonte formal principal)é a lei, enquanto as demais são as fontes formais acessórias, também ditas secundárias.

22 Viver honestamente, não lesar a ninguém, dar a cada um o que é seu.
} 
Esse é "novo" Estado de Direito que se assenta na era Pós-Positivista - o Estado centrado na materialidade dos conteúdos fundamentais e na preeminência dos princípios. Dessa forma, há uma constitucionalização dos princípios gerais de Direito - unificação dos princípios gerais de direito em torno dos princípios constitucionais - onde esses se revestem "do prestígio e da hegemonia que se confere às normas inseridas na Lei das leis. Com essa relevância adicional, os princípios se convertem igualmente em norma normarum (...)" (BONAVIDES,2008, p. 290). Em razão disso, Paulo Bonavides (2008, p. 648), analisando a chamada "Nova Hermenêutica Constitucional de Concretzação", concebe que essa hermenêutica concretiza o preceito constitucional, pois que concretizar é mais que interpretar: é interpretar com acréscimo, com criatividade. Oriunda do Princípio da Unidade da Constituição, essa Hermenêutica de concretżação ${ }^{23}$ possibilita a introdução do conceito de juiz social, "enquanto consectário derradeiro de uma teoria material da constituição, e, sobretudo, da legitimidade do Estado social e seus postulados de justiça, inspirados na universalidade, eficácia e aplicação imediata dos direitos fundamentais. Aqui, relevante o ensinamento de Gordillo Cañas ${ }^{24}$ (1988) apud Paub Bonavides (2008, p. 291), quando conclui que esse Estado de Direito, ancorado na materialidade dos valores constitucionalmente albergados, inaugura uma tríade de trabalho - legislador, juiz e Tribunal Constitucional - os três, "convocados a impla ntar a concepção principial do ordenamento jurídico na sua 'tendência, sempre por alcançar, de perfeita explicitação e aplicação normativa'”.

Dessa ordem jusconstitucional, em oposição à juscivilística clássica, onde os princípios serviam à lei, pode-se afirmar: os princípios encabeçam o sistema, logrando vabração normativa suprema, qualidacte de instância juspublic ística primária, sede de toda a legitimidade do poder (BONAVIDES, 2008, p. 293). De um lado, esse "Estado Principial” (BONAVIDES, 2008, p. 293), resultado das transformações operadas no Estado de Direito, desde o Liberalis mo Clássico, até a presente "Era dos Princípios", favorece a realização dos postulados maiores da justiça e da dignidade, afastando aquele tecnicismo das regras e outorgando ao sistema jurídico maior flexibilidade e dinamismo. De outro bdo, a consequente "remodelagem" da função jurisdicional trazida pela Teoria dos Princípios pode resvalar em um decisionismo irrazoável,

\footnotetext{
23 A Corte de Karlsruhe sentenciou "Não se pode considerar insuladamente uma estipulação singular da Constituição nem pode ser ela interpretada 'em si mesma', senão que deve manter 'conexão' de sentido com as demais prescrições da Constituição, formando uma unidade interna”. (BONAVIDES, op. cit. p.595).

24 CAÑAS, Antônio Gordilho. Ley, principios generales y Constitución: apuntes para uma relectura, desde la Constitución, de la teoria de las fuentes del Derecho. Anuario del Derecho Civil.t. LXI, fasc.2, abr/jun. 1988.
} 
baseado em devaneios subjetivos, ao contrário de orientar o exercício do poder para a efetivação dos valores fundamentais prescritos pelo ordenamento jurídico constitucional. Mister, portanto, buscar, por dentro da Teoria dos Princípios, parâmetros para evitar os riscos oriundos de um exercício jurisdicional mal conduzido, resultado de uma panaceia principiológica.

\section{Por uma necessária conclusão: Como controlar as artimanhas da desrazão maquiavélica?}

Sem embargo, é possível se verificar um grande "perigo" nas mãos dos operadores do direito, quando da prática desvirtuada da Teoria dos Princípios. Como exemplo retumbante dessa situação: decisões lastreadas em valores e sentimentos pessoais, sob o manto do "Juiz maquiavélico", como se retratassem fundamentações constitucionalmente valoradas. Utiliza-se a expressão "Juiz maquiavélico", para "diagnosticar", aquele que promove suas decisões, segundo seus fins (unilateralidade), com base nos seus próprios meios (motivação pessoal), ancorado, de fato, em um discurso de irracionalidade egocêntrica, ao contrário do que se propõe na Teoria Material da Constituição, albergada na extensão objetivamente valorada dos princípios. Esse "desgoverno de Juźes maquiavélicos” é o que Paub BONAVIDES (2008, p. 646) chama de "governo de juízes" ou de "ditadura constitucional da toga". Nessa direção, Lenio STRECK (2005, p. 310) elucida que não se deve admitir um processo de discricio nariedade desregrada do intérprete na aplicação da norma: “(...) a afirmação 'a norma é (sempre) o produto da atribuição de sentido a um texto' não pode significar que o intérprete esteja autorizado a 'dizer qualquer coisa sobre qualquer coisa"' [grifo nosso]. Um nítido exemplo dessa "hermenêutica maquiavélica" aparece em votos como o elaborado pelo Ministro Humberto Barros, no STJ (AgRg em ERESP 279.889AL). In verbis:

\footnotetext{
Não me importa o que pensam os doutrinadores. Enquanto for ministro do Superior Tribunal de Justiça, assumo a autoridade da minha jurisdição. O pensamento daqueles que não são ministros deste Tribunal importa como orientação. A eles, porém, não me submeto. Interessa conhecer a doutrina de Barbosa Moreira ou Athos Carneiro. Decido, porém, conforme minha cons ciência. (...). Esse é o pensamento do Supe rior Tribunal de Jus tiça e a doutrina que se amolde a ele. É fundamental expressarmos o que somos. Ninguém nos dá lições. Não somos apre ndizes de ninguém. [grifo nosso].
}

Ao contrário do que originalmente se propõe, uma constitucionalização "aleatória" do Direito pode levar: a) Do ponto de vista políico, a uma tirania da minoria, instrumentalizada 
pela obliteração da legislação ordinária; b) Do ponto de vista epistemológico, a uma sacralização do decisionismo maquiavélico - ativismo ilimitado do Poder Judiciário. Nesse sentido, a advertência de GALVÃo (2014, p. 312), segundo a qual, o mau uso dos Princípios, no limite, conduziria ao fim do Estado de Direito e seu principal Princípio informador - a legalidade: “(...) Ao dissipar a densidade normativa das normas jurídicas e autorizar os juízes a decidirem com base em preferências pessoais, o Neoconstitucionalismo gopeia com intensidade o conceito de Estado de Direito, aproximando-o do fim" (GALVÃO, 2014, p. 312). Com a lucidez, que the é constante, elucida Lenio STRECK (2013, posição 1742):

(...) não é (mais) necessário dizer que o "juiz não é a boca da lei”, etc., enfim, podemos ser poupados, nesta quadra da história, dessas "descobertas polvolares". Isto porque essa "descoberta" não pode implicar um império de decisões solipsistas, das quais são exemplos as posturas caudatárias da jurisprudência dos valores (que foi importada de forma equivocada da Alemanha), os diversos axiologismos, o realismo jurídico (que não passa de um "positivismo fático"), a ponderação de valores (pela qual o juiz escolhe um dos princípios que ele elege prima facie), etc. [grifo do autor].

Com base nas premissas levantadas neste texto, pergunta-se, então: Quais seriam os limites da atuação Jùz frente ao Princípio Constitucional da Separação dos Poderes? Como controlar as artimanhas dessa desrazão maquiavélica??? Como estabelecer uma críica epistemo lógica aos "ativismos judiciais irresponsáveis, seja isso, para o bem ou para o mal" (STRECK, 2013, posição 1835)?

Ora, o Direito é carente de uma Teoria que incorpore valores institucionalmente objetivados, quais sejam daqueles resultantes de "um exercício constante de pensamento dos conceitos jurídicos fundamentais de modo a problematizar seus limites, demarcando seu campo de atuação" (STRECK, 2013, posição 1845). Por isso, com base, sobretudo, na "resposta correta" em Dworkin e na "correção da interpretação"25, proposta pela Filosofia Hermenêut ica de Hans-Georg Gadamer, esse trabalho apresenta suas diretrizes de sugestão para a delimitação de um núcleo objetivo de legitimação do Poder Jurisdicional. É a linha de trabalho criada/perseguida por Lenio STRECK (2013, p. 1874, grifo nosso): “(...) a nova Crítica do Direito ou a Crítica Hermenêutica do Direito é uma nova teoria que exsurge da fusão dos horizontes da filosofia hermenêutica, da hermenêutica filosófica e da teoria integrativa dworkiniana". Dito isso, seguem-se as diretrizes supracitadas: 1) Concepção de Democracia

Substancial - "resultado" da mediação entre as reivindicações atuais da sociedade, 25 Ver ST RECK, 2013, posição, 2167 . 


\section{ancoradas na Constituição, e os valores inalienáveis do indivíduo, cuja relativização}

\section{histórica não é sinônimo de interesses exclusivamente particulares: A Filosofia de Hans-}

Georg Gadamer vai dizer que o núcleo central do problema hermenêutico está exatamente na relação entre o Universal e o particular: "compreender é, então, um caso especial da aplicação de algo geral a uma situação concreta e particular” (GADAMER, 1999, 465). Não há "separação" entre texto e norma, pois que não há ser sem ente. O que surge à compreensão do intérprete é, desde o "segundo Heidegger", o ser do ente, que aparece na linguagem ${ }^{26}$ :

(...) a linguagem é o médium universal em que se realiza a própria compreensão. A forma de realização da compreensão é a interpretação. Essa constatação não quer dizer que não exista o problema particular da expressão. A diferença entre a linguagem de um texto e a de seu intérprete, ou o abismo que separa o tradutor de seu original, não são, de modo algum, uma questão secundária. Bem pelo contrário, os problemas da expressão linguística já são, na realidade, problemas de compreensão. Todo compreender é interpretar [o sentido do ser], e todo interpretar se desenvolve no medium de uma linguagem que pretende deixar falar o objeto [o ser] e é, ao mesmo tempo, a linguagem própria de seu intérprete [cada interpretação parcial] (GADAMER, 1999, 566-567, grifo do autor).

\footnotetext{
26 Nos seus primeiros escritos, à época de "ser e tempo", Heidegger preocupa-se com uma hermenêutica do Dasein, ou seja, na análise fenomenológica do ser-no-mundo. No segundo Heidegger, ou ainda, na sua filosofia posterior. Heidegger preocupa-se mais com a problemática da exegese da compreensão. Ou seja, como é que se pode compreender o ser? Ou, como o ser tornou-se compreendido? Richard Palmer (1999, p. 146) ao tratar da análise (provocada na produção teórica de Heidegger) da subdivisão do pensamento heideggeriano em duas etapas diferentes traz a seguinte interpretação: Do início ao fim de sua obra, Heidegger preocupa-se com o processo hermenêutico, pelo qual o ser se revela. Isso foi abordado em ser e tempo como uma fenomenologia do Dasein e tornou-se em suas obras subsequentes, numa exploração do não ser, da própria palavra ser, de concepções quer gregas quer atuais de ser, de verdade, de pensamento e de linguagem. É um facto aceite que Heidegger se tornou mais poético, obscuro e profético nos seus últimos escritos, mas que a revelação do ser se mantém nele como um tema constante. Hans-Georg Gadamer, como "bom" discípulo, acompanhando esse sentido de continuidade no traçado teórico de Martin Heidegger, desenvolveu as implicações da contribuição do seu mestre para a hermenêutica (tanto as do "ser e Tempo", como as de ulteriores obras) num trabalho sistemático que conceituou de Filosofia Hermenêutica. Sobre essa questão comenta Palmer (1999, p. 170): "[Gadamer] propõe uma dialética baseada na estrutura do ser como foi explicada pelo último Heidegger, e na estrutura prévia da compreensão tal como se coloca em ser $e$ Tempo". Gadamer entendeu o pensamento de Heidegger também constituído de uma única peça que desde "ser e Tempo" até seus escritos ulteriores caminha em direção ao chamamento [o "apelo"] do ser, radicada em cada temporalidade e individualidade. Sobre isso, Gadamer (1999, p. 398-399, grifo nosso), adverte: “(...) Caberia indagar também o que significa que a existência humana encontre sust entação, por sua vez, em algo extra-histórico, natural. Se se quer romper o cerco da especulação idealista, não se pode evidentemente pensar o modo de ser da "vida" [do ser, de Deus] a partir da autoconsciência. Quando Heidegger em preendeu a revisão de sua autoconcepção filosófico-transcendental de ser e tempo [a viragem ou viravolta], o problema da vida teria de chamar-lhe a atenção novamente e de modo consequente. Assim na Canta ao hum anismo fala do abismo que se abre entre o homem eo animal". Também Gadamer (1999, p. 398-399) continua advertindo aqueles que em vez de entender o pensamento de Heidegger como uma caminhada única, procuraram tratá-lo como uma tarefa subdividida e submetida a uma revisão de direcionamento ou "virada" de sentido: "Não há dúvida de que a fundament ação transcendental da ontologia fundamental realizada por Heidegger na analítica da pré-sença ainda não permitia o desenvolvimento positivo do modo de ser da vida. Aqui ficaram questões abertas. Todavia, tudo isso não muda nada no fato de que se perde completamente o sentido do que Heidegger chama "existencial" [ec- sistencial], quando se crê poder opor ao existencial da 'cura' um determinado ideal de existência, seja lá qual for. Quem faz isso perde a dimensão do questionamento que ser e tempo abre desde o princípio. Face a essas polêmicas míopes, Heidegger podia apelar com razão à sua intenção transcendental, no mesmo sentido em que era transcendental o questionamento kantiano. $\mathrm{O}$ seu questionamento estava desde os seus primórdios [até seus escritos ulteriores], acima de toda diferenciação empírica e, por consequência também de toda diferenciação de conteúdo. Dessa sorte, Gadamer deu uma outra apresentação à hermenêutica geral das ciências do espírito (Geisteswissenschaften). Seu trabalho teórico seguiu os passos da contribuição de Heidegger acerca da estrutura geral da compreensão. Partindo de uma crítica da hermenêutica vista por Schleiermacher e Dithey, Gadamer chega a Heidegger e sustenta que toda compreensão dá-se no caráter histórico da compreen são como um ec-sistencial. A partir de uma "perspectiva essencialmente heideggeriana" (PALMER, 1999, p.167). Gadamer (1999, p. 16) assume que: "a compreensão nãoé um modo de ser, entre outros modos de comportamento do sujeito, mas o modo de ser da própria pré-sença (Dasein).
} 
Conclui-se que a dimensão da pré-compreensão não é um campo de especulação arbitrária, afetando a segurança jurídica e a unidade do texto constitucional. Ora, as características pré-conceituais ${ }^{27}$ estão em constante reorientação, permanecendo em jogo; não cedendo às pressões da soberania da subsunção normativa. A compreensão pressupõe uma précompreensão e ela não ocorre sem uma dimensão projetiva que antecipa o sentido: “(...) $\mathrm{O}$ círculo hermenêutico é um círculo rico em conteúdo (inhaltlich erfülltt), que reúne o intérprete e seu texto numa unidade interior a uma totalidade em movimento (processual whole). A compreensão implica, sempre, uma pré-compreensão que, por sua vez, é prefigurada por uma tradição determinada em que vive o intérprete e que modela os seus preconceitos" (GADAMER, 1998b, p.13). Essa "ligação" entre intérprete e texto busca a criação de seu sentido normativo consciência jurídica geral - dentro da estrutura histórico-constitucional, a que pertence o exegeta judicial, limitando a sua atuação exclusivamente relativista. Por isso, Lenio Streck afirma que (2013, posição 1864): “interpretar é aplicar; (...) os sentidos somente se manifestam no ato aplicativo". Do ponto de vista da decisão judicial, a relevância na pré- compreensão é proporcional à obediência do compromisso constitucional e à legislação democraticamente construída, no interior das quais, também, há a discussão das questões ético- morais da sociedade. Esse compromisso com a Constituição é o alicerce, onde se problematiza a tensão hermenêut ica entre integridade com a Constituição e o ativismo judicial. Dessa forma, é necessário buscar um elemento de estabilização do Sistema, qual seja, a proteção de um núcleo essencial, como "topos" de conformação objetiva dos direitos fundamentais, democraticamente construídos. O elemento estabilizador serve, simultaneamente, a orientação geral e a criatividade, delimitando a arbitrariedade de decisões, cunhadas em "dizer qualquer coisa sobre qualquer coisa", que se encaixe como ponderação de "princípios aleatórios" (STRECK, 2013, posição 2323). 2) Por uma integridade da decisão judicial - quando a fundamentação deve “desvelar" a "resposta correta", qual seja, aquela baseada no aporte

constitucional substancial: Lenio Streck (2013, posição 1874) contextualiza essa diretriz da

\footnotetext{
${ }^{27}$ Para Gadamer, os conceitos prévios não constituemalgo que possamos aceitar ou recusar, mas eles são a base da capacidade que temos para compreender a his tória (PALMER, 1999, p. 185-186). Em toda compreensão somos carregados pela corrente da vida histórica.
} 
seguinte maneira: “(...) há um direito fundamental a uma resposta correta, entendida como adequada à Constituição (...)", que "somente tem sentido na democracia e sob a égide de uma Constituição compromissória". E mais, incita, como principal problema da Crítica Hermenêutica do Direito, (2013, posição 1884): “(...) como ocorre e dentro de quais limites deve ocorrer a decisão judicial'? Para isso, no caminho da Crítica Hermenêutica do Direito, fecundada por Lenio Streck, postulam-se princípios orientadores - de Dworkin e de Gadamer: 2.1) qualquer decisão "deve tratar todos os cidadãos como iguais, isto é, como tendo direitos iguais, interesse e respeito. (...) "nenhuma decisão possa [pode] impor deliberadamente a algum cidadão um risco de dano moral muito maior do que impõe a outro" (DWORKIN, 2001, p. 124) - A decisão judicial não está fora do mundo do cidadão da pólis: É substancialmente político-constitucional, sendo uma "decisão de princípio". À luz de Gadamer (1999), ela é intrínseca ao problema da história efeitual ${ }^{28}$. Gadamer (1999, p. 451) constata que a tarefa da hermenêutica filosófica é ter de "refazer o caminho da fenomenologia do espírito hegeliana até o ponto em que, em toda subjetividade, se mostra a substancialidade que a determina". "Aquele que compreende já está sempre incluído num acontecimento, em virtude do qual se faz valer o que tem sentido" (GADAMER, 1999, p.708) [grifo nosso]. O acontecimento não está circunscrito à contingência meramente individual e à vida privada. "Na medida em que compreendemos, estamos incluídos num acontecer da verdade e quando queremos saber o que temos que crer, parece-nos que chegamos demasiado tarde" (GADAMER, 1999, p. 708). 2.2) O segundo princípio orientador "refere-se à equidade de sujeitar-se a compromissos abertos, justos quando adotados - à equidade de, por exemplo, acatar resultado de um lance de cara ou coroa, quando ambas as partes concordaram razoavelmente quanto ao jogo" (DWORKIN, 2001, p. 124) - Nada mais do que Gadamer (1999) conceitua como jogo (spiel) ${ }^{29}$ : “O que entra ou está em jogo já não depende de si mesmo, mas é dominado por essa rehção chamada jogo. Para o indivíduo, que se entrega ao jogo, como subjetividade lúdica, isso pode parecer, de início, uma adaptação. A gente se ajusta ou se submete ao jogo, isto é, recusa-se à autonomia da própria vontade" (GADAMER, 2002, p. 154).

\footnotetext{
28 A Filosofia Hermenêutica promove a revitalização da força da obra de arte para a vida [o acontecimento], considerando o aspecto pedagógico da compreensão como uma forma de diálogo com a história.

29 “(...) Aquele que compreende já está sempre incluído num acontecimento, em virtude do que se faz valer o que tem sentido. (...) Ele ganha validez e já sempre nos atraiu para si, antes mesmo que alguém caia em si e possa

examinar a pretensão de sentido que o acompanha. O que nos vem ao encontro na experiência do belo e na compreensão do sentido da tradição tem realmente algo da verdade do jogo. (...). Assim, é certo que não existe compreensão que seja livre de todo preconceito, por mais que a vontade do nosso conhecimento tenha de estar sempre dirigida, no sentido de escapar ao conjunto dos nossos preconceitos" (GADAMER, 1999, p. 708-709).
} 
Com bases nesse dois princípios, extraídos da Teoria gadameriana e dworkiniana, consegue-se delimitar possíveis saídas para as incompreensões geradas pelo individualismo judicial dogmático, onde se “(...), reconhece-se o primado do jogo em face da consciência do jogador (...)" (GADAMER, 1999, p. 178). Nesse sentido, "um pensamento verdadeiramente histórico [constitucional-democrático] tem de pensar, ao mesmo tempo, a sua própria historicidade [constitucionalidade]", onde "aprenderá a conhecer, no objeto [constitucional], o diferente do próprio [não constitucional] e conhecerá, assim, tanto um como o outro" (GADAMER, 1999, p. 448). Assim, a decisão judicial deve assegurar: “(...) que as questões mais fundamentais de moralidade política serão finalmente expostas e debatidas como questões de princípios e não apenas como questões de poder político (...)" [grifo nosso]. Nesse caminho, Lenio Streck (2013, posição 2002) considera que as condições de possibilidade da decisão judicial é uma questão de democracia. Essa é a "integridade", que deve nortear a decisão judicial - onde a situação de cada pessoa seja justa e equitativa, segundo as mesmas normas. A integridade não admite que uma comunidade personificada aplique direitos diferentes, que não podem ser definidos como um conjunto coerente com os princípios de justiça, equidade e devido processo legal (DWORKIN, 2003, p. 201-202).

\section{Referências Bibliográficas.}

ALEXY, Robert. Teoria dos direitos fundamentais. Trad. Virgílio Afonso da Silva. São Paulo: Malheiros, 2008.

ALMEIDA, Custódio Luís Silva de; FLICKINGER, Hans-Georg; ROHDEN, Luiz. Hermenêutica filosófica: nas trilhas de Hans-Georg GADAMER. Porto Alegre: EDIPUCRS, 2000.

ARAÚJO CINTRA, Antônio Carlos; et, Ada Pellegrini; DINAMARCO, Cândido Rangel. Teoria geral do processo. 24.ed. São Paulo: Malheiros Editores LTDA, 2008.

ÁVILA, H. Teoria dos princípios: da definição à aplicação dos princípios jurídicos. 16. ed. São Paub: Malheiros, 2015.

BARROSO, Luís Roberto. Fundamentos teóricos e filosóficos do novo direito constitucional (pós-modernidade, teoria crítica e pós-positivismo). In: A nova interpretação constitucional. Rio de Janeiro: Renovar, 2006. 
BONAVIDES, P. Curso de direito constitucional. 23. ed. São Paub: Malheiros, 2008.

CHAVES DE FARIAS Cristiano; ROSENVALD Nelson. Teoria geral do direito. Rio de Janeiro/RJ: Lumen Juris Ltda, 2011.

CONJUR. Dica de leitura. Disponível em: < http:/www.conjur.com.br/2012-jul-06/ideo logiapessoatdefine-decisoes- juizes-estudo-ufpr >. Acesso em 02 mai 2015.

DELFINO, Lúcio \& FERREIRA LOPES, Ziel A expulsão do livre convencimento motivado do Novo CPC e os motivos pelos quais a razão está com os hermeneutas, 2015. Disponível em: $<$ http://justificando.com/2015/04/13/aexpulsaodolivreconvencimento motivadodono vocpc eosmoti vospelosquaisarazaoestacomoshermeneutas/ >. Acesso em 02/05/2015.

DWORKIN, Ronald. Uma questão de princípio. São Paub: Martins Fontes, 2000. . O império do direito. São Paub: Martins Fontes, 2003.

FERRAZ JÚNIOR Tercio Sampaio. Introdução ao estudo do direito: técnica, decisão, dominação. SAO PAULO: Editora Athas S.A, 2003.

GADAMER, Hans-Georg. O problema da consciência histórica. Org. Pierre Fruchon; Trad. Paub César Duque Estrada. Rio de Janeiro: Fundação Getúlio Vargas, 1998b.

. Verdade e método: traços fundamentais de uma hermenêutica filosófica.

Trad. Fávio Paulo Meurer. 3. ed. Petrópolis, RJ: Vozes, 1999. (Pensamento Humano).

. Verdade e método II: complementos e índice. Tradução Ênio Paulo Giachini. Petrópolis, RJ: Vozes, 2002. (Pensamento Humano).

GAJARDONI Fernando da Fonseca. O livre convencimento motivado não acabou no novo CPC. Disponível em: http//jota.info/olivreconvencimentomotivadonaoacabounonovocpc>. Acesso em: 02 mai 2015.

GALVÃO, Jorge Octávio Lavocat. O neoconstitucionalismo e o fim do Estado de Direito. São Paub: Saraiva, 2014.

LÔBO, Paub Lùz Netto. Teoria geral das obrigações. São Paub: Saraiva, 2005.

LYOTARD, Jean-François. O pós-moderno. 4. ed. Rio de Janeiro: José Olympio, 1993.

MARINONI, Lu̇ Guilherme. Teoria geral do processo. 3.ed. São Paub: Revista dos Tribunais, 2008.

PALMER, R. E. Hermenêutica. Lisboa: Edições 70, 1999.

STRECK, Lenio Luiz. Hermenêutica jurídica e $(m)$ crise. Porto Alegre: Livraria do Advogado, 2005. 
Da Interpretação de Textos à Concretização de Direitos: a incindibilidade entre interpretar e aplicar a partir da diferença ontológica entre texto e norma. Constituição, sistemas sociais e hermenêutica: programa de pós-graduação em Direito da Unisinos: mestrado e doutorado / orgs. André Copetti, Lenio Luiz Streck, Leonel Severo Rocha ... [et al]. Porto Alegre: Livraria do Advogado Ed.; São Leopoldo: Unisinos, 2006.

STRECK, Lenio Luiz. Verdade e consenso: Constituição, Hermenêutica e Teorias Discursivas. Da possibilidade à necessidade de respostas corretas em direito. $2^{\mathrm{a}}$ ed. Rio de Janeiro: Lume $\mathrm{n}$ Juris Editora, 2007.

. O que é isto - decido conforme a minha consciência?. 4. ed. Porto Alegre: livraria do Advogadao, 2013.Kindle Edition.

. A estória da 'Katchanga Real' - Recolocando as coisas no lugar ou de como se pode 'Katchangar' sem se dar conta de que se está 'Katchagando' - Uma homenage m a Luis Alberto Warat, 2012. Disponível em: < http://professormedina.co m/2012/02/28/aestoria-da-katchanga-real-por-lenio-streck/ >. Acesso em 11 jun. 2015.

- Senso incomum: Dilema de dois juízes diante do fim do Livre Convencimento do NCPC. São Paub: Consultor Jurídico, 2015. Disponível em: < http://ww w.conjur.co m.br/2015- mar-19/senso-inco mum-dilema-do is-juizes-diante-fim-livre convencimento-ncpc >. Acesso em 02 mai 2015.

TARTUCE. Flávio. Direito civil: Lei de introdução e parte geral São Paulo: Método, 2007. WEBER, Max. The methodology of the social sciences. New York. Glencoe. Ed. Edward Shills. 1949. 1964. . Basic concepts in sociology by Max Weber. New York. The Citadel Press. 